\title{
La prensa popular durante el régimen de Fujimori: a propósito de las formas de una práctica de recepción
}

\author{
Recibido: 19 de noviembre de 2014 \\ Aceptado: 11 de junio de 2015 \\ Publicado: 30 de octubre de 2015
}

\author{
Miguel Ángel Torres Vitolas \\ matorres@pucp.edu.pe
}

Pontificia Universidad Católica del Perú

\begin{abstract}
Resumen: En la década de los noventa, bajo el régimen de Fujimori, el panorama de la prensa en el Perú conoció el auge de la prensa popular. Esta tuvo una relación bastante particular con el gobierno y a menudo cumplió con la estrategia comunicativa de este gobierno, lo que se observó en la forma de presentar de modo positivo al candidato-presidente y difamar a los opositores. Desde una perspectiva semio-pragmática, el presente artículo señala las constantes narrativas y semánticas presentes en los contenidos comunicados por las portadas de estos diarios y pone en relación las estrategias discursivas desplegadas con las prácticas de recepción correspondientes.
\end{abstract}

Palabras clave: Semiótica, semio-pragmática, prensa popular, recepción, autoritarismo.

Abstract: Under Fujimori's regime, Peruvian Press knew the explosion of Popular Press. This one had a very special relationship with Fujimori's regime and his communication strategies. It could be seen through positive president representations and contenders defamation. Following a semio-pragmatic approach, this article underlines narrative and semantics constants present in media content through this press in their first page and put discursive strategies deployed in relation with reception practices.

Key words: Semiotics, Semio-pragmatics, Popular Press, Reception, Autoritarism.

\section{Introducción}

En Ciudadano Kane (1941), Orson Welles propone un retrato cruel y descarnado de un joven empresario (Kane) que decide ingresar al mundo del periodismo y de los medios porque cree "que será divertido dirigir un periódico". Adquiere así un diario en problemas 
económicos (The Inquirer) y va poco a poco haciéndose de un conjunto de medios que están bajo su dirección. Conforme la historia avanza, Kane se sirve del poder de los medios que maneja tanto para sus fines políticos (su candidatura) como personales (para inventar la carrera musical de su segunda esposa). Kane da forma a su manera de manejar los medios con la idea de que estos le permiten manipular la decisión que tomarán sus lectores.

Kane llega así a declarar en algún momento: "todo el mundo va a pensar que yo les ordene que piensen". La película de Orson Welles, que no gratuitamente se inspira en el magnate de la prensa William Randolph Hearst, describe así cómo las ambiciones personales y políticas pueden interponerse en el rol informativo de la prensa y, más grave aún, cómo este afán manipulatorio puede llegar a ser exitoso. Se trata de representaciones de la prensa y del público que trascienden la ficción y que son a menudo evocadas cuando se trata del rol político de los medios.

Cuando ciertos momentos de tensión social y política aparecen, la forma en que estos son representados por la prensa es a veces señalada por los mismos políticos. Partidos de gobierno y opositores llegan así a indicar como unos y otros tienen de su lado a los medios. El rol político que la propia prensa puede cumplir es así determinado para subrayar su falta de transparencia y el papel determinante que puede cumplir. En las últimas campañas electorales presidenciales (las elecciones del 2011) o en las elecciones municipales del 2010, situadas dentro de una situación política bastante polarizada, pudimos ver la reaparición de las acusaciones de manipulación de la información y de prácticas de difamación mediática hacia un sector mayoritario de la prensa. Aquello de lo que se le acusa en estos momentos críticos no es exactamente de tomar partido abiertamente por un candidato o una línea política, sino más bien de ocultar su toma de posición haciendo difusos los límites entre la información y la propaganda. La estrategia de comunicación criticada es entonces aquella de la desinformación con un objetivo político.

El presupuesto que subyace a estas acusaciones es el de los efectos que la propaganda y la difamación pueden producir en el público y, por consecuencia, en el electorado. Como Kane en la película, la prensa podría devastar las aspiraciones políticas de un candidato y conseguir entronizar a otro. Esto se debe a que la imagen que se ha formado de la relación entre medios y público es a menudo la del enorme poder de ellos y la fragilidad de este último. Se los estima entonces capaces de manipular, así como de educar y se teme los alcances de este gran poder.

Pese al desarrollo diverso de la investigación en comunicación, desde las hipótesis de la Escuela de Frankfurt o el Two-step Flow de Lazarsfeld (Lazarsfeld y Katz, 1955), hasta la corriente de "usos y gratificaciones" de Fiske (1987), no se puede dejar de admitir que esta imagen de los medios está aún muy fijada en una buena parte de los imaginarios. Esta manera de comprender la relación con los medios corresponde a lo que Staiger (2005: 1819), en el panorama que ella propone sobre los paradigmas de la recepción en las ciencias humanas, describe como los modelos educativo y del reforzamiento. Se trata, en el primer modelo, de entender a los medios como entidades que irremediablemente, lo deseen o no, cumplen un rol de formación al transmitir contenidos que, bajo este paradigma, son asimilados por los receptores sin mayor discusión. En el caso del modelo del reforzamiento, 
la imagen del receptor no es distinta, pero la de los medios es comprendida bajo la forma de entidades que ayudan a perpetuar el statu quo al transmitir contenidos que reafirman el orden establecido (ibídem).

Nos parece evidente que dentro de los imaginarios que circulan, cuando se discute el rol de los medios, son estas imágenes las que son evocadas. Para los políticos, la posibilidad de controlar estos medios aparece así como la oportunidad de conseguir el favor de los electores y de servirse de estas herramientas de comunicación para vencer a sus rivales. En este sentido, la tentación de controlar estos medios de comunicación, considerados tan poderosos e influyentes, ha formado a menudo las relaciones que se han creado entre los medios, como instituciones, y los Estados.

Para comprender mejor el paisaje mediático peruano y el rol de la prensa en la política es necesario volver un poco atrás y examinar un caso en que la campaña de desinformación política fue tan virulenta y grosera que fue también, finalmente, bastante transparente. Nos referiremos al caso de la prensa peruana en los años noventa y, particularmente, al caso de la prensa popular, que se tornó cada vez más importante hacia el final de dicha década. El final del gobierno de Fujimori, con los cambios políticos y sociales que suscitó, significó también cambios importantes en el paisaje mediático del país: las acusaciones de manipulación y difamación han dado lugar a procesos judiciales que han llevado a la sentencia y prisión de dueños de canales de televisión, de prensa escrita y de agencias de comunicación. Se trata, así, de un episodio que ha llegado a fines judiciales que no se han conocido de modo similar antes.

El interés de nuestro artículo es de abordar la presencia cada vez más importante de la prensa popular en el paisaje de la prensa escrita del país y su relación con la estrategia de comunicación observada durante el gobierno de Fujimori. Nuestro objetivo es mostrar que esta prensa no puede ser comprendida solamente a partir de las relaciones que tuvo con el gobierno. Nuestros objetivos son, así, fundamentalmente dos: a) ver la relación que se estableció entre el gobierno y los medios y comprenderla en el marco del precedente inmediato de intervención de la prensa que se conoció en la época de Velasco; y, desde un ángulo semio-pragmático, b) comprender la estrategia de comunicación del gobierno frente a la práctica de recepción que daba sentido a los contenidos que se buscaban transmitir.

El modo en que realizaremos este análisis sigue, de un lado, el camino de examinar las formas de control y de presión que ejerció el Estado sobre los medios en la época de Fujimori. Apoyándonos en un análisis semiótico y semántico del discurso, señalaremos las características de las constantes semánticas presentes en la prensa popular de entonces. Finalmente, desde un ángulo semio-pragmático, propondremos de qué modo se pueden entender las prácticas de recepción que daban sentido a las estrategias de comunicación desplegadas desde el Estado. Nuestro interés, en un sentido más amplio, es el de comprender por qué la prensa popular (con las características con que se la conoció entonces y sus formas de comunicación) no han desaparecido con el final del gobierno de Fujimori, sino que, más bien, estas se han adaptado fácilmente a los cambios políticos que se han producido desde entonces. 


\section{Precedentes}

El adjetivo con el que se define a esta prensa puede resultar engañoso, pues conduce a creer de modo inmediato en una categoría claramente delimitada. Lo popular no constituye una categoría en sí, sino más bien una manera de imaginar al público $\mathrm{y}$, su vez, de considerar la manera de dirigirse a este. En ese sentido, concordamos con Martín Barbero en la idea de que lo popular ha adquirido formas particulares históricamente en el modo en que los medios se han asumido en casos determinados como populares:

"En el terreno cultural la masificación consiste en el proceso de inversión de sentido mediante el cual pasa a denominarse 'popular' en el siglo XIX la cultura producida industrialmente para el consumo de las masas. Es decir, que en el momento histórico en que la cultura popular apunta a su constitución como cultura 'de clase', esa misma cultura va a ser minada desde dentro, hecha imposible y transformada en cultura de masa. Pero a la vez esa inversión solo es posible por la cercanía que en el siglo XX guarda aún la masa de 'las masas', de manera que la nueva cultura popular se construye activando ciertas señas de identidad de la vieja cultura y neutralizando o deformando otras" (Martín Barbero, 1982).

Podemos afirmar, en ese sentido, que si algo caracteriza a la prensa que denominamos "popular" es que esta determina en su modelo económico y cultural a la "masa" a la que pretende dirigirse. Su estrategia comercial asume un nivel adquisitivo para este público, así como sus estrategias discursivas presuponen un horizonte cultural de referencia y de interés. En virtud de la caracterización de esta "masa", esta prensa se adapta a ella y a su vez le da forma al lector ideal que presupone.

La prensa popular no apareció durante el régimen de Fujimori, aunque sí adoptó entonces muchas de las características que la identifican hoy en día. Es el caso de las características plásticas de sus portadas (los colores llamativos, el tipo de letra muy grande en los titulares y la exposición de alguna modelo en poses sugestivas), así como la preeminencia concedida a los personajes del mundo del espectáculo. Para comprender la evolución de esta prensa hacia esas formas que se fijaron en la década de los noventa (y que aún conocemos) es pertinente situarla en la perspectiva de aquella que la precedió.

Una breve historia de la prensa popular señala como precedentes los diarios La Crónica y Última Hora, fundados en los años cuarenta y cincuenta respectivamente. Encontramos además a Extra (1965) y Ojo (1968), con el paréntesis forzoso que significó para toda la prensa el régimen militar de los años sesenta, del que hablaremos luego, y la aparición del diario El Popular en los años ochenta.

En el caso de Última hora, en 1950, encontramos la lógica de comunicar a través del empleo de una variable sociolectal baja (el argot urbano) y la constante semántica de dar una importancia mayor al deporte y al espectáculo. Se señala precisamente a Última hora como el diario que inaugura la presencia de este lenguaje en la prensa popular ( $c f$. Gargurevich, 1991: 181). Es así célebre el titular que inaugura el empleo de este lenguaje: "Chinos 
como cancha en el paralelo 38"1 (9/XII/1950). Los titulares de Última hora no van solo a alimentarse del lenguaje popular, sino que introducen otro elemento característico de esta prensa en el Perú: el recurso del registro cómico en torno a la información, así sea un tema político o una nota policial. Dentro de las formas de la prensa popular peruana, el discurso no asume así solo una forma informativa y persuasiva, sino que además integra siempre el lenguaje de la broma sobre lo referido.

El inicio del primer mandato de Fujimori se produce en el marco de una prensa de información dentro de la cual la presencia de la prensa popular es minoritaria. Hacia el final de su mandato, el panorama es totalmente distinto. La década de los noventa vio así aparecer los diarios El Mañanero (1993), Ajá (1994), El Chino (1995), La Chuchi (1996), El Chato y El Tío (1998), La Yuca, El Polvorín y Vistazo (2000), entre otros. En mayo del 2000, momento de la segunda reelección de Fujimori, había en Lima 17 diarios populares, de los cuales 15 tenían una línea editorial favorable al régimen ( $c f$. Fowks, 2000: 70). Sólo esta diferencia en el número de diarios de este tipo en circulación y su mayoritaria inclinación política (favorable al régimen) nos indican ya que algo había ocurrido en estos años y que difícilmente puede llegar a comprenderse lo que ocurrió como una suma curiosa de coincidencias.

No debe olvidarse que desde el primer mandato de Fujimori, las reglas del juego habían comenzado a cambiar para la prensa. Las reformas neoliberales del gobierno modificaron la estructura económica sobre la cual la actividad comercial de los diarios funcionaba con el fin de la excepción fiscal por la importación de papel y materiales de impresión, para los periódicos y editoriales ( $c f$. Wood, 2000: 29). En el marco de las distintas reformas económicas de corte neoliberal que caracterizaron este gobierno (reducción del gasto público, privatizaciones, etc.), los medios se vieron confrontados a un cúmulo de deudas que condujo en 1994 (año anterior a la primera reelección de Fujimori) a un acuerdo entre estos medios asociados y la SUNAT para refinanciar su deuda. Este modo de refinanciamiento muestra bien las relaciones de dependencia económica entre los medios (la prensa y la televisión) y el Estado: una parte de la deuda podía ser intercambiada por la difusión de publicidad del Estado (Wood, 2000: 30). Los medios endeudados se ven entonces en cada vez mayor dependencia de la publicidad estatal.

Es dentro de estas nuevas condiciones que, en la segunda mitad de la década de los noventa, el número de diarios populares aumentó considerablemente. Aparecen así los diarios $L a$ Chuchi, La Yuca, El Tío, El Men, entre otros. Si estos continúan, en un principio, la lógica de los diarios populares que les precedieron, es decir, una preeminencia de las noticias policiales y de la información relativa al espectáculo y los deportes, comienzan también a tomar una posición política muy clara, especialmente cuando las elecciones presidenciales se aproximan y se conoce que, a pesar de su ilegalidad, Fujimori piensa presentar su candidatura a un tercer periodo en la presidencia. Estos emprenden una abierta campaña favorable al presidente candidato, así como una importante campaña de difamación contra

1. El titular hace referencia a la presencia de la armada china en el paralelo 38 en 1950, frente a la armada americana y surcoreana, en el contexto de la guerra de Corea. 
los opositores al gobierno, políticos y periodistas, que son acusados de corrupción, de simpatizantes de Sendero Luminoso, de adicciones, o simplemente tratados de homosexuales (cualidad desde luego disfórica en el contexto peruano).

Podemos así leer un titular abiertamente difamatorio: "Somos Kutra de Andrade quería traficar con lotes de terreno del pueblo" (La Chuchi, 19/II/2000). El titular identifica así al partido de Alberto Andrade con la corrupción, por un sencillo juego de palabras que altera el nombre de su partido ("Somos Perú"), a la vez que reseña un acto de corrupción aparentemente constatado. La recurrencia del sema "ilegal" sobre los sememas de "Kutra" y "traficar" da forma a un fondo de sentido, un horizonte de coherencia, que denominamos en semántica textual y en semiótica la "isotopía” ( $c f$. Greimas y Courtés, 1979; Courtés, 2003: 103-105). Este rasgo semántico sitúa al personaje político sobre un fondo de sentido que lo desvaloriza. Se trata, como veremos, de una práctica común y constante en la prensa popular de esos años ( $c f$. Gargurevich, 2000: 283-291).

Frente a una campaña tan transparente de difamación y a la acusación de parte de diversos organismos nacionales e internacionales por dichas prácticas (pero, sobre todo, frente a la desigual presentación de los candidatos en los medios durante la campaña electoral del 2000) el gobierno de Fujimori pudo siempre servirse del argumento de la libertad de empresa y de información para excusarse de intervenir o, a posteriori, de la acusación de haber intervenido. La idea que se plantea es que los empresarios dueños de los medios decidieron libremente orientar la línea editorial de sus diarios y canales en favor del gobierno, así como otros pocos (con igual libertad) decidieron hacer lo contrario. La prueba de ello se encontraría en que el gobierno no introdujo cambios legales que señalan un medio de presión ideológico sobre la prensa. Dentro del marco jurídico existente, no se podía ir preso ni ser expulsado del país (como en otros tiempos y en otros contextos ha ocurrido) por ser un opositor al régimen.

En una buena parte de estos casos será hacia el final del régimen de Fujimori que la estrecha relación entre los medios y el gobierno terminó por hacerse pública, tanto al nivel del financiamiento como de los contenidos divulgados. El peculiar circuito por el que se concebían estos titulares difamatorios y aquellos elogiosos del presidente, desde las oficinas del Servicio de Inteligencia Nacional (SIN) hasta las imprentas de los diarios, fue motivo de muchas especulaciones y no se comprendió con claridad sino luego del debacle del régimen ${ }^{2}$.

\footnotetext{
2. Se pudo así conocer que los titulares eran enviados desde las oficinas del SIN y que los propietarios de los diarios recibían un pago por cada publicación con recursos del Estado. Por ejemplo, el director y propietario de El Tío, José Olaya Correa, recibió, entre 1998 y el 2000, 1,5 millones de dólares (Conaghan, 2002: 117119). El publicista Augusto Bresani actuaba muchas veces como intermediario entre Vladimiro Montesinos y los propietarios de estos diarios ( $c f$. Fowks, 2000: 70-74).
} 


\section{Por una aproximación semio-pragmática de las prácticas de comunicación y recepción}

Dentro de la tradición del análisis narrativo en semiótica, heredera de Propp, la propuesta de Greimas fue la de llegar a un nivel de representación de una abstracción mayor que la de las funciones que había deducido Propp para el análisis de los cuentos folklóricos rusos. La propuesta de Greimas, que ha sido luego continuada por la semiótica canónica y, por lo menos en lo que respecta al análisis narrativo, también por corrientes semióticas más recientes es la de reconstruir la lógica del relato a partir de la transformación principal que en él se realiza ( $c f$. Propp, 2006; Courtés, 2003: 88-91; Greimas y Courtés, 1979). Es en función de este reconocimiento de la narrativa que condujo a un estado final que se deducen los estados anteriores y que son comprendidos todos ellos en la lógica de un esquema narrativo en que se relacionan la competencia, la performance y la sanción.

La performance describe la transformación principal que se produce en el relato, en tanto la competencia muestra de qué saberes, motivaciones y capacidades estaba dotado el sujeto operador de la transformación, y la sanción señala qué recompensa o castigo recibe el sujeto operador de la transformación por haber sido agente del cambio producido en el relato. En la lógica del análisis narrativo se trata entonces de comprender el relato como la operación de un cambio (la performance), de comprender los antecedentes que lo permitieron (la competencia) y las consecuencias que le sucedieron (la sanción). Trataremos de entender lo que describen algunos titulares de la prensa popular en el sentido de la lógica narrativa que describen; es decir, quién aparece como el sujeto operador, qué transformación realiza éste y quiénes son los sujetos que se oponen a la performance. Abordaremos también en ellos, desde la semántica textual, bajo qué coherencia semántica son presentados y caracterizados los actores que realizan estos distintos roles actanciales.

Si el intrincado proceso de financiamiento y la cadena de responsables en este complejo caso es todavía motivo de procesos judiciales, lo que incluso entonces no era difícil de establecer es a quién se buscaba beneficiar y a quién dañar dentro de la campaña de comunicación que esta serie de titulares describían. Los titulares de los diarios populares muestran fácilmente el sentido que se le quería dar al espacio político, bajo una axiología que presentaba de forma eufórica al gobierno (con la figura central del actor "Fujimori") y de forma disfórica a los opositores del régimen (en este caso, las figuras son más diversas, los actores en cuestión podían ser tanto políticos como periodistas).

Un examen rápido de estos titulares nos muestra que los valores que son adheridos a la figura del presidente, por medio de aferencias contextuales y de aferencias socialmente normadas ( $c f$. Rastier, 1989: 280) son aquellos del /trabajo/, del /esfuerzo/ y de la/proximidad/ con la gente: "Arequipa votará por Fuji el 28, chamba y paz", "Ventanilla y Comas se juegan por entero por el Chino. Con Fuji habrá chamba para todos los peruanos" ( $E l$ Chino, 22-23/V/2000). La figura del "Chino" remite así a esta lectura, que se apoya además en el estereotipo del asiático trabajador que está aún presente en la sociedad peruana. Es en dicho sentido que consideramos que estos semas se actualizan de un modo socialmente normado. Ello quiere decir que se trata de significaciones que aparecen no por invención 
del contexto lingüístico sintagmático, sino por actualización de significaciones presentes socioculturalmente.

Los titulares recogidos describen así una estructura narrativa que podemos describir de la siguiente manera: Fujimori aparece como el "actor-destinador" que conseguirá, superando numerosas pruebas y adversarios, el objetivo de conducir al país y a los peruanos (los “actores-destinatarios") hacia el progreso (representado como el acceso a los servicios básicos, a la vivienda y al trabajo).

Los opositores a Fujimori no son solo descritos de forma disfórica por quiénes son, sino también por su oposición a esta performance descrita para el presidente. Ante este programa narrativo descrito para él, ellos aparecen entonces como quienes realizan el antiprograma opuesto. Leemos así: "Chancho Andrade pide sembrar el terror a sus cascos azules" (La Chuchi, 14/II/2000). El entonces alcalde de Lima y candidato a la presidencia, Alberto Andrade, aparece abusando de su poder y descrito de un modo grosero en razón de su sobrepeso. Como en otro ejemplo citado anteriormente ("Somos Kutra de Andrade quería traficar con lotes de terreno del pueblo") se trata de relacionar a los oponentes a Fujimori con ciertos valores disfóricos y de insistir sobre estos rasgos (la /corrupción/ en el caso de Alberto Andrade, por ejemplo).

Un análisis de contenido de los titulares de estos diarios proporciona una imagen bastante clara del paisaje político que el gobierno deseaba comunicar. Un análisis semántico y semiótico clásico permitiría retener, sin mayores dificultades, las isotopías predominantes en estas publicaciones, tanto al nivel de sus titulares como del contenido mismo de los diarios. Podemos así reconocer la recurrencia isotopante del sema /ilegal/ en los titulares referidos a Alberto Andrade en los ejemplos dados. Del mismo modo podría observarse la práctica de situar a Fujimori del lado eufórico de la organización axiológica que se le da al espacio político.

Una descripción de este tipo, sin embargo, no nos permite comprender cómo esta estrategia de comunicación se vio confrontada a las prácticas de recepción. En ese mismo sentido, no nos permite comprender cómo esta estrategia de propaganda y difamación se inscribe dentro de un proyecto, más extenso y más complejo, de confusión de los límites entre la información y el entretenimiento en los medios que se formó en esos años y que, como modelo, ha persistido hasta nuestros días. Lo que nos interesa entonces es, más bien, esta confrontación entre una estrategia de comunicación y las prácticas de recepción, pues ello nos permitirá comprender mejor lo que ocurrió en los años noventa en el Perú y por qué estas formas de comunicación han podido reaparecer en campañas políticas más recientes.

Al realizar esta reorientación del interés (de las formas inmanentes del texto a las de la relación que se forma entre el contexto significante y las prácticas de recepción) estamos siguiendo la perspectiva de interés de la semio-pragmática en lugar de la semiótica canónica greimassiana. Como señala Odin (2011: 17-19), en esta perspectiva se trata de señalar al contexto como el punto de partida de la producción del sentido, lo que sugiere entender que es el contexto el que determina esta producción. En ese sentido, nos parece más pertinente 
para comprender lo que ocurrió en aquellos años y lo que ocurre actualmente con esta prensa: privilegiar un análisis de estrategias y de prácticas antes que un análisis de contenido.

Nuestro estudio se inscribe así en la línea de interés descrita por Martín Barbero, quien propone el paso de los medios a las mediaciones y privilegia el análisis de las relaciones sociales que toman forma dentro de estos objetos culturales (Martín Barbero, 1991: 220-229). Como lo resume Rueda (2010: 11), retomando a Martín Barbero: "La perspectiva de la mediación pretende decriptar los objetos culturales que circulan en los medios, participan en la fabricación de los imaginarios y son también habitados por ellos, y cuya recepción supone prácticas culturales colectivas y procesos identitarios"3. Es de alguna manera el interés descrito por Eric Maigret y Macé en Francia con las nociones de las "mediaculturas" y de los "imaginarios mediáticos" (Maigret, 2005: 17-66).

Desde la semiótica, Fontanille (2008) ha propuesto el que podría ser un mejor camino a seguir en el análisis, tanto para una perspectiva semiótica como para una centrada en la recepción que quiera ajustarse a las formas del contenido. Dada la diversidad de los objetos culturales que han sido abordados por la disciplina y la dificultad que puede haber para tratarlos como textos, el mencionado autor sugiere abordar el proceso de la significación dentro del cuadro de las prácticas significantes que dan forma a la enunciación, al enunciado, a la recepción y a las interacciones. Se trata entonces de considerar una aproximación englobante que integre al objeto estudiado dentro de la práctica significante en la cual se inscribe, en la que aparece y que es la que permite, entonces, de tratarlo como un texto.

De esta forma, (Fontanille, 2008: 17-78) propone comprender la práctica a partir de la integración de diferentes niveles de pertinencia: el texto, el objeto, las escenas prácticas, las estrategias, las formas de vida. Lo que nos interesa particularmente en esta propuesta es la idea de comprender de una forma englobante el proceso de la significación, lo que permite integrar en él a la enunciación y la recepción y precisar para el caso de cada práctica estudiada los elementos constituyentes y su nivel de pertinencia. Los elementos llamados "contextuales", que bajo una perspectiva restringida de la noción de "texto", aparecen como inabordables, reencuentran así el lugar que les corresponde. Esta propuesta permite también tomar en cuenta las tensiones posibles entre la enunciación, de forma generalmente programática en la comunicación mediática, y la recepción, que podrá eventualmente intentar reajustarse ante ese programa previsto. Fontanille sostiene así que "una de las dimensiones esenciales del análisis de las prácticas semióticas será el de ocuparse de esta tensión permanente entre la acomodación programada y la acomodación inventada, entre la pre-esquematización y la apertura a la alteridad; en breve, entre programación y reajuste"4 (ibídem: 5).

3. "L'approche par la médiation prétend décrypter les objets culturales qui circulent dans les médias, participent à la fabrication des imaginaires et sont à la fois habités par eux, et dont la réception entraine des pratiques culturelles collectives et des processus identitaires" (texto original).

4. “[...] l'une des dimensions essentielles de l'analyse des pratiques sémiotiques tiendra à cette tension permanente entre l'accommodation programmée et l'accommodation inventée, entre la préschématisation et l'ouverture à l'altérité; bref, entre programmation et ajustement" (texto original). 
Ello abre espacio a un estudio de las interacciones con una mirada similar a aquella que también ha propuesto Landowski (2006) desde la socio-semiótica. Esta apertura nos permite integrar al análisis las posibilidades de acomodación en las interacciones, de manera de no concebir toda relación entre el medio y el receptor únicamente como una manipulación, sino que se podrán integrar también las posibilidades de la acomodación y el reajuste que posee el lector. Esto quiere decir que (como Landoswki lo propone para comprender las interacciones sociales) es concebible, en incluso deseable, dentro de una perspectiva semiótica, abordar las posibilidades de reajuste de las contrapartes frente al hacer programático (ibídem: 16-25 y 39-53).

Esto es imprescindible, ya que si es cierto que los actores de la enunciación en la comunicación mediática buscan normalmente obtener una respuesta precisa de parte del receptor (una adhesión al discurso, la fidelización a un diario, etc.), no es menos correcto señalar que el receptor, a su vez, posee cierto margen de maniobra frente a esta estrategia. El interés de abordar la perspectiva de la recepción sería precisamente el de ver cuáles son estas estrategias de reajuste que despliega el receptor. Desde un ángulo semiótico, entonces, se trata de entender que las prácticas significantes, tanto en producción como en recepción, toman sentido en la dinámica entre las formas persuasivas desplegadas en la estrategia de comunicación y las formas adaptativas que se realizan en recepción.

\section{Formas de la recepción y de la comunicación}

Es interesante a este respecto observar el caso de la prensa bajo el régimen de Fujimori en la perspectiva de lo que ocurrió en el país durante el periodo autoritario anterior (la dictadura militar de Juan Velasco Alvarado entre 1968 y 1975). Dado que en ambos casos los gobiernos intervinieron la prensa para controlar los contenidos difundidos por ella, es pertinente señalar cómo este control fue ejercido.

En el caso del gobierno de Velasco, el control se realizó (desde un primer momento) a través de la presión judicial impuesta a los medios, dentro de un marco legal que permitía expulsar del país a aquellos que se consideraba publicaban información falsa con el fin de desestabilizar al gobierno. El precedente legal había sido dado por las leyes creadas durante el gobierno de Odría ( $c f$. Wood, 2000: 18), lo que permite en ese sentido decir que las expulsiones de periodistas que ocurrieron dentro del gobierno de Velasco fueron hechas al amparo de un marco legal.

En vista que el gobierno de Velasco deseaba realizar reformas profundas en lo relativo a la propiedad de los terrenos agrícolas (reforma agraria) y las explotaciones mineras, la prensa (que pertenecía en su mayor parte a las familias de la élite nacional) se mostró abiertamente opuesta a dichas medidas, a las que trató abiertamente de comunistas (ibidem: 19). Frente a esta situación, el paso final tomado por este régimen en el control de la prensa fue el de expropiar los diarios y los canales de televisión, dentro del marco del Plan Inca (1974).

La relación entre el gobierno y la prensa bajo el régimen de Fujimori fue más compleja, pues esta fue menos transparente. Se puede en un principio afirmar que (como Fujimori y 
sus partidarios se encargan de recordar) bajo su gobierno no se aprobó ninguna ley similar a aquellas invocadas y puestas en ejecución bajo el régimen de Velasco. El marco legal de la propiedad de la prensa no conoció ningún cambio importante durante la época de Fujimori, ni este intervino directamente contra la propiedad de los medios. La presión sobre estos fue más bien indirecta, a través de la dependencia de estos de la publicidad del Estado y la presión de la SUNAT.

Lo que se ha conocido luego de la caída del régimen fue el empleo de medios directos (pero ilegales) para obtener el apoyo de diarios y de canales de televisión. Los casos más notorios son sin duda los de los "vladivideos" registrados en las oficinas del SIN, donde se pudo observar a propietarios de canales de televisión (Ernesto Schutz, de Panamericana Televisión, y José Enrique Crousillat, de América Televisión) recibir millones de dólares por parte de Vladimiro Montesinos. Más allá del acto inmoral e ilegal, lo que nos interesa señalar es que el marco legal en la relación entre los medios y el Estado no cambió.

Un caso más bien excepcional fue el del propietario de Frecuencia Latina, Baruch Ivcher, a quién se le despojó de la propiedad del medio mediante una argucia legal. Al desconocerse su nacionalidad peruana no pudo ya asumir la propiedad de un medio de comunicación y ello permitió al gobierno de tener al frente de este canal a personas más próximas a sus intereses. Aún dentro de esta farsa legal, lo que podemos observar es que no se expropió al dueño original del medio porque haya contravenido alguna ley que impedía la transmisión de ciertos contenidos, sino que el asunto se manejó dentro de la figura legal de un problema entre partes privadas.

Es dentro de la complejidad de esta relación con la prensa que podemos encontrar la pista de la estrategia de comunicación del gobierno. Esta pasa por la apariencia formal de una libertad de prensa, bajo la forma de un supuesto respeto de la libertad empresarial (mientras que el régimen de Velasco optó por intervenir directamente rompiendo con esta libertad de empresa), así como un desdibujamiento de los límites entre el discurso informativo y el entretenimiento, favorecido por el estilo de las portadas de los diarios populares. Este desdibujamiento de los límites de los géneros discursivos banaliza el lugar de la política en los medios y hace así menos disonante la presencia tan abierta del recurso a la propaganda y a la difamación.

El caso de la prensa popular es ejemplar porque esta busca (dentro de su modelo económico) la comunicación con los sectores desfavorecidos. Si, como lo hemos señalado, bajo el régimen de Fujimori el número de este tipo de diarios aumentó considerablemente, podemos también constatar que el lugar preponderante que se le concedió al espectáculo y al deporte en este tipo de diarios encontró un correlato en otros medios (radio y televisión) particularmente durante los periodos electorales ( $c f$. Fowks, 2000: 65-66; Gargurevich, 2000: 264-269). Podemos así plantear que la reducción del espacio concedido a los temas políticos y la confusión de los contornos (entre aquello que corresponde al discurso informativo y aquello que remite al entretenimiento) fueron parte de la política de comunicación del gobierno. En el caso de la prensa popular, la banalización de la información participó en el desdibujamiento de los límites, hasta entonces mal que bien respetados, entre la información política, la policial y la del espectáculo. 
Para comprender cómo estas formas de comunicación se integraron del lado de los receptores, debemos comprender una práctica de lectura corriente en los medios urbanos en el Perú: el modo de presentación de los diarios y la forma de lectura de estos por parte de los transeúntes. En los medios urbanos, los diarios son puestos en venta en kioscos o en la misma calle en los distritos de la ciudad. En los diversos kioscos (formales o informales) las portadas de los diarios son expuestas unas junto a las otras, formando una suerte de mosaico informativo. En este mosaico encontramos la totalidad de los diarios en venta. Los diarios más tradicionales (como El Comercio y La República) se encuentran así junto a Trome y El Popular.

La práctica de recepción de los peruanos (en medios urbanos) frente a esta forma particular de presentación de los diarios es la de detenerse un momento a mirar este muro o mosaico informativo (de camino o de regreso del trabajo, esperando un bus) sin necesariamente terminar por comprar alguno de estos diarios. El lector recorre las portadas deteniéndose de un modo distinto por ellas pues algunas pueden atraer más su atención. La copresencia en que estas se presentan hace, sin embargo, que siempre tenga alguna impresión, así sea esta muy superficial, sobre el conjunto de estas. Se trata de una práctica que no se restringe únicamente a los sectores populares, pues este modo de exposición de los diarios puede encontrarse en los distintos barrios de las ciudades del país.

Lo que sugerimos, entonces, es que los peruanos en los medios urbanos no son nunca los lectores de un diario o dos, sino que son siempre los lectores de las portadas de todos los diarios en circulación, expuestos bajo la forma señalada. La portada de un diario no constituye entonces solo una invitación a comprar y leer el diario, sino que dentro de la lógica de esta práctica de recepción (errática y momentánea que el peruano común realiza todos los días), se constituye por entero en el texto y la información que son comunicados. Dentro de la dinámica de la práctica de recepción que hemos señalado, la portada es además parte constituyente del mosaico informativo en el que se inscribe. Como a menudo ocurre, el lector puede no adquirir un diario, por lo que su percepción del paisaje informativo, político y cultural, pasa por el mosaico de portadas observado.

Es dentro de esta lógica que la presencia masiva de diarios populares abiertamente favorables al régimen y contrarios a todos sus oponentes (en la época de Fujimori) consiguió desdibujar los límites entre la información política y el entretenimiento, y reafirmar las isotopías que eran ya redundantes en la mayoría de los diarios que eran de este modo expuestos. La noción de isotopía que señalábamos antes nos es aquí bastante pertinente, pues ella señala la redundancia de semas (rasgos semánticos) que da un fondo de coherencia a un texto. Lo particular de nuestro caso, visto en la lógica de la práctica de recepción descrita, es que la redundancia sémica no se produce para el lector únicamente sobre la portada de un diario, sino sobre el conjunto de diarios que su lectura recorre en el mosaico. Dentro de él encontraba una misma lógica en la presentación de los actores y de los temas (la construcción del actor Fujimori y de los valores de los que era investido, así como aquellos señalados para sus opositores).

La estabilidad semántica de la comunicación transmitida encuentra, entonces, todo su sentido por la copresencia de informaciones similares sobre la mayoría de diarios en cir- 
culación. Lo que la recurrencia de los mismos contenidos y constantes semánticas en estos diarios conseguía así era dar forma a un paisaje político, social y cultural que no por redundante y monótono dejaba de ser coherente. Es de ahí que proviene la importancia de controlar los contenidos que aparecen sobre estas portadas.

El mecanismo, que conocemos mejor ahora, indica que los titulares de las portadas eran concebidos y enviados desde el SIN, por vía telefónica o por medio de emisarios, a los diarios, donde el director de la publicación hacía algunos cambios y se ocupaba de la diagramación para, finalmente, antes de remitirlo a imprenta, enviarlo una vez más al SIN para una última confirmación ( $c f$. Fowks, 2000: 71-72). Dado que la práctica de lectura descrita encontraba como horizonte de pertinencia no solo la portada sino el mosaico formado por ellas, la forma que se daba a estas describía un paisaje político para los lectores.

Esta estrategia de comunicación toma entonces sentido porque ella se integra a las prácticas de recepción formadas en la vida corriente de los medios urbanos del país. En el mismo sentido, la circulación de la información que pasa por esta mediación se nutre del lenguaje popular urbano, así como de los imaginarios mediáticos y populares. No se trata así de una comunicación artificial impuesta de arriba hacia abajo, desde el poder hacia el público, sino más bien de una integración en la comunicación de los imaginarios y lenguajes de las clases populares así como de sus prácticas de lectura. Ello produce un efecto de coherencia del sentido (los lectores reencuentran los mismo referentes, los mismo lenguajes) al tiempo que sitúa sobre el mismo plano a los actores de la vida política y del espectáculo.

\section{Conclusiones}

Comprender las estrategias de comunicación que están en juego en los diarios populares exige de nuestra parte situarlos frente a las prácticas de recepción constituyentes de los modos de vida y de las prácticas significantes de la vida corriente. En este sentido, el caso de la prensa popular en el Perú nos lleva a reflexionar sobre los modos de consumo y de lectura de la información en el país.

Se ha escrito mucho sobre las formas manipuladoras de esta prensa en el tiempo de Fujimori, pero, al mismo tiempo, se ha obviado el comprenderlas dentro de la lógica de las prácticas de lectura que les daban sentido. Al respecto, hemos podido observar que las constantes narrativas y semánticas presentes en las portadas de la mayoría de los diarios populares en circulación en aquella época conseguían proponer un discurso coherente sobre el universo político y cultural porque su exposición en forma de un mosaico de portadas era aquella a la que accedía la población en los contextos urbanos.

A la estrategia de comunicación que se desplegaba desde el gobierno le correspondía así una práctica significante en recepción. Un trabajo que todavía debe realizarse sería el de pensar, de un modo más global, en la integración de las estrategias de comunicación y de las formas de recepción, los imaginarios retomados y representados, así como las formas plásticas reutilizadas. 


\section{Fuentes consultadas}

Conaghan, C. (2002). "Cashing in on Authoritarianism: Media collusion in Fujimori's Peru”. The Harvard International Journal of Press Politics, núm. 7, pp. 115-125.

Courtés, J. (2003). La sémiotique du langage. París: Nathan.

Fiske, J. (1987). Television culture. Londres: Methuen.

Fontanille, J. (2008). Pratiques Sémiotiques. París: Presses universitaires de France.

Fowks, J. (2000). Suma y resta de la realidad. Medios de comunicación y elecciones generales 2000 en el Perú. Lima: Fundación Friedrich Ebert.

Gargurevich, J. _(2000). La prensa sensacionalista en el Perú. Lima: Fondo Editorial PUCP. _(1991). Historia de la prensa peruana (1594-1990). Lima: La Voz Ediciones.

Greimas, A. y Courtés, J. (1979). Sémiotique. Dictionnaire raisonné de la théorie du langage. París: Hachette.

Landowski, E. (2006). "Les interactions risquées". Nouveaux Actes Sémiotiques, núms. 101,102 y 103.

Lazarsfeld, P. y Katz, E. (1955). Personal Influence. Nueva York: Free Press.

Maigret, E. (2005) “Qui a peur d'une politique des représentations?”, pp. 17-66. En Maigret, E. y Macé, E. (eds.). Penser les médiacultures. París: Armand Colin.

Martín Barbero, J.

_(1991). De los medios a las mediaciones. Comunicación, cultura y hegemonía. México D. F.: Gustavo Gili.

_(1982). “Apuntes para una historia de las matrices culturales de la massmediación”. Ponencia para el Primer Foro Internacional de la Comunicación Social-Comunicación y Poder. Lima.

Odin, R. (2011). Les espaces de communication. Grenoble: Presses Universitaires de Grenoble.

Propp, V. (2006). Morfología del cuento. Madrid: Fundamentos.

Rastier, F. (1989). Sens et Textualité. Poitiers: Hachette.

Rueda, A. (2010). "Des médias aux médiations: quelles médiations, quels objets, quels enjeux?". Dosier Les Enjeux de l'information et de la communication, pp. 88-103. 
Staiger, J. (2005). Media Reception Studies. Nueva York: New York University Press.

Welles, O. (dir.) (1941). Ciudadano Kane [película]. Hollywood: Mercury Productions, RKO Pictures.

Wood, D. (2000). "The Peruvian Press under recent authoritarian regimes, with special reference to the autogolpe of President Fujimori". Bulletin of Latin American Research. Vol. 19, núm. 1, pp.17-32. 